\title{
UMA GOTA AMARGA: ITINERÁRIOS DA NACIONALIZAÇÃO DO ENSINO NO BRASIL
}

\section{RESENHA}

QUADROS, Claudemir de (org.). Uma gota amarga: itinerários da nacionalização do ensino no Brasil. Santa Maria: Editora UFSM, 2014.

\section{Cassiane Curtarelli Fernandes ${ }^{1}$}

lattes.cnpq.br/5088256139945535

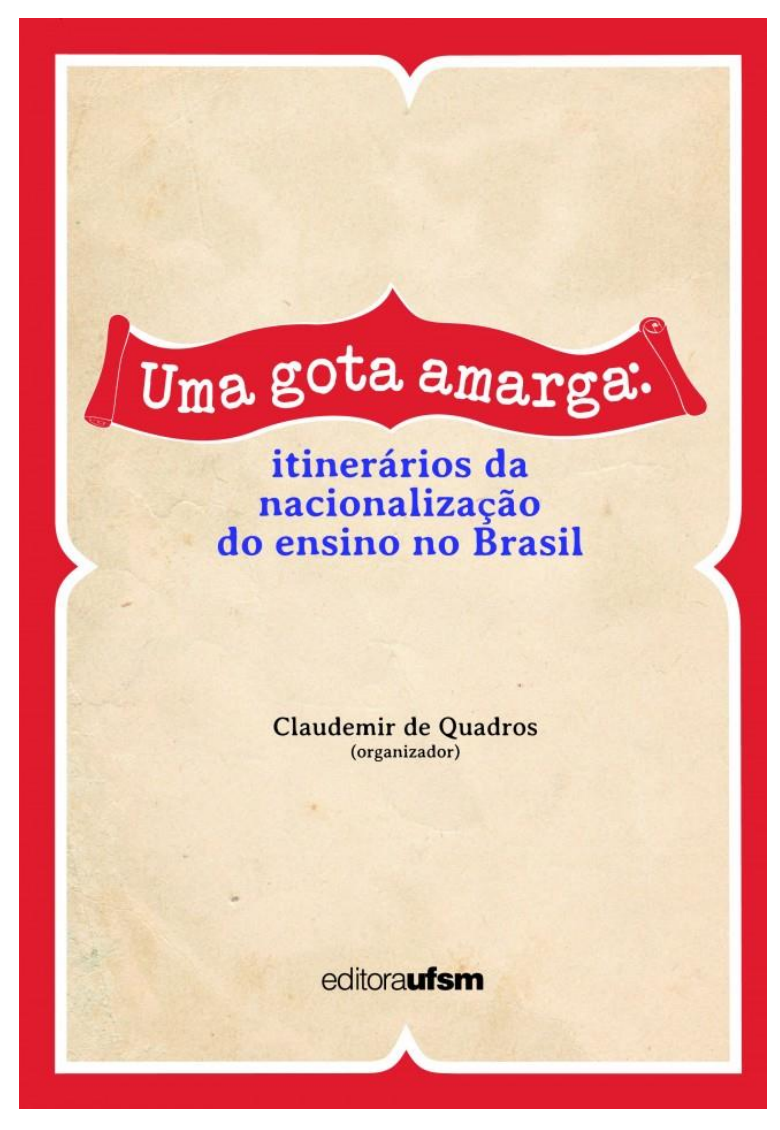

A obra intitulada Uma gota amarga: itinerários da nacionalização do ensino no Brasil, organizada pelo professor Claudemir de Quadros, é um convite à leitura para os pesquisadores interessados na temática da nacionalização do ensino no Brasil. Publicado em 2014, o livro é composto por onze capítulos que apresentam como recorte temporal o período que vai da Primeira República até a consolidação do Estado Novo, utilizando como cenário os estados do Rio Grande do Sul, do Paraná e de São Paulo.

A partir de diferentes olhares de pesquisadores consagrados no campo da História da Educação no Brasil, a obra apresenta as marcas e as representações construídas na história da escola, por meio da campanha de nacionalização implantada pelo Presidente Getúlio Vargas, em uma

\footnotetext{
${ }^{1}$ Mestre em Educação pela Universidade de Caxias do Sul (Brasil). Contato: cassianecfernandes@gmail.com.
} 
época em que a escola foi vista como um espaço privilegiado de disseminação da cultura nacional, com o intuito de se forjar uma nova identidade brasileira.

No primeiro capítulo, Etnias e nacionalização no Sul do Brasil, o historiador René Ernaini Gertz discute as relações existentes entre as concepções de Estado e de Nação no Brasil, especialmente em relação à campanha de nacionalização implantada nos estados de Santa Catarina e Rio Grande do Sul. O texto chama a atenção para as medidas nacionalizadoras que atingiram de diferentes formas e em diferentes momentos o meio educacional dessas Regiões.

O segundo capítulo, organizado por Dorval do Nascimento, intitulado Brasilidades, Lusitanidades, Germanidades: a política de nacionalização do ensino primário e as disputas em torno da Nação (1934-1945), reflete sobre as medidas de nacionalização do ensino que foram implantadas durante o Ministério de Gustavo Capanema. Medidas que visavam, entre outras questões, instaurar o sentimento de brasilidade nas novas gerações, motivo que levou a escola primária a ter "um papel fundamental em todo o processo" (NASCIMENTO, 2014, p. 65).

A nacionalização do ensino e a renovação educacional no Rio Grande do Sul é o título do terceiro capítulo, escrito por Maria Helena Camara Bastos e Elomar Callegaro Tambara. No texto, são abordadas questões referentes ao processo de nacionalização e renovação pedagógica no estado na primeira metade do século XX, que produziram modificações no trabalho docente, na legislação escolar, nos métodos de ensino, no currículo, nas finalidades da educação, entre outras transformações atravessadas também pelo discurso da Escola Nova.

Claudemir de Quadros é o autor do quarto capítulo, intitulado $O$ discurso que produz a reforma: nacionalização do ensino, aparelhamento do Estado e reforma educacional no Rio Grande do Sul (1937-1945). José Pereira Coelho de Souza, quando assume a Secretaria de Educação e Saúde Pública do Rio Grande do Sul, dá início a um intenso processo de reformas educativas no estado, visando, entre outras questões, ampliar a rede de ensino, orientar, supervisionar e inspecionar o trabalho desenvolvido nas 
escolas estaduais, objetivando contribuir para a campanha de nacionalização implantada por Vargas em todo o território nacional.

Além de discorrer acerca das escolas estrangeiras, representadas como um perigo no período em questão, Claudemir de Quadros apresenta ao leitor que o processo de reforma educacional, ocorrido no estado, favorecido pela campanha de nacionalização do ensino, alterou intensamente as formas de gestão do sistema escolar no Rio Grande do Sul, especialmente a partir da organização do Centro de Pesquisas e Orientações Educacionais - CPOE/RS.

Ao analisar as políticas públicas de nacionalização das escolas étnicas no Rio Grande do Sul, entre os anos de 1900 a 1940, o professor Lúcio Kreutz, autor do quinto capítulo, intitulado A nacionalização do ensino no Rio Grande do Sul, medidas preventivas e repreensivas, aponta as características e a constituição dos primeiros cem anos das escolas étnicas no estado, bem como escreve sobre a nacionalização progressiva dessas instituições apontando as medidas preventivas e repressivas implantadas pelo governo gaúcho, com o intuito de formar uma identidade nacional desejada.

O texto Abrasileirar os coloninhos: histórias e memórias escolares na região colonial italiana do Rio Grande do Sul (1937-1945), de autoria da professora Terciane Ângela Luchese, compõe o sexto capítulo do livro apresentado. $\mathrm{O}$ trabalho de Luchese permite compreender os discursos e as práticas de nacionalização que estiveram representadas na história da educação da região colonial italiana a partir de três enfoques abordados pela autora: as políticas públicas para a educação, o ensino e o uso da língua portuguesa e as práticas de nacionalização efetivadas no cotidiano escolar.

Dóris Bittencourt Almeida, ao narrar à história do Colégio Farroupilha, fundado por imigrantes alemães, na cidade de Porto Alegre/RS, escreve o sétimo capítulo, que intitula como As marcas do novo: do Colégio Alemão ao Colégio Farroupilha. Nesse capítulo, Almeida apresenta as relações entre a campanha de nacionalização e as transformações ocorridas na história institucional do Colégio a partir do olhar de ex-alunos e dos periódicos escolares analisados por ela. Compreende também que, embora 
o Estado Novo tenha deixado marcas na trajetória da instituição, ele não fez com que a cultura alemã desparecesse completamente daquele espaço educativo.

O oitavo capítulo, escrito por Elaine Cátia Falcade Maschio, intitulado Os imigrantes italianos, seus descendentes e suas escolas frente às campanhas de nacionalização do ensino em Curitiba/Paraná (190o1930), atenta para a história da colonização italiana em Curitiba e o processo de escolarização das colônias, bem como reflete sobre as medidas de nacionalização ocorridas no estado do Paraná, com ênfase nas escolas italianas.

Versando sobre a imigração de poloneses e ucranianos no no Paraná, Valquíria Elita Renk é a autora do nono capítulo, O processo de nacionalização das escolas étnicas polonesas e ucranianas no Paraná. Valquíria objetiva analisar "como as escolas e as comunidades étnicas garantiram a manutenção da identidade étnica e quais foram as formas de resistência ante a nacionalização simbólica" (RENK, 2014, p. 292).

O décimo capítulo, intitulado História com muitos poréns: a nacionalização das escolas criadas por imigrantes alemães em São Paulo, de Maria Cristina dos Santos Bezerra, reflete acerca do impacto causado pelas políticas de nacionalização na organização das escolas germânicas do estado paulista.

Encerrando a obra, o décimo primeiro capítulo, produzido por Eliane Mimesse Prado, intitulado Vislumbre acerca da nacionalização do ensino: o enigma das escolas que italianizaram a cidade de São Paulo, investiga a constituição das escolas italianas paulistas, nas primeiras décadas do século XX, e aponta as medidas criadas pelo governo para nacionalizar a infância.

Ao finalizar a leitura desta obra, depois de entrar em contato com as pesquisas desenvolvidas ao longo dos últimos anos por cada um dos autores acima, é inegável a importante contribuição do livro para a história da escolarização no Brasil, especialmente no que tange o período da nacionalização do ensino. Um momento que marcou profundamente o cotidiano 
e as culturas escolares de muitas escolas brasileiras, especialmente aquelas localizadas nas zonas rurais dos estados, organizadas pelas comunidades de imigrantes e seus descendentes.

Destaco a relevância da temática abordada para as investigações no campo da história da educação, sobretudo para a área da história das instituições escolares, por oferecer um embasamento teórico consistente acerca dos motivos, dos reflexos e das transformações ocasionadas pela campanha de nacionalização do ensino, principalmente entre os anos de 1937 a 1945, quando se torna compulsória.

Cumpre ressaltar a riqueza do estudo para se pensar as dinâmicas de vida dos sujeitos escolares, sobretudo, de alunos e de professores, atravessadas pela imposição do uso do português, pela comemoração das festas e celebrações cívicas, pelo silenciamento de suas identidades e culturas, pelo culto aos heróis nacionais, entre outras práticas, repletas de traumas e inseguranças para os imigrantes e descentes, uma vez que a gota amarga derramada por muitos, fez parte do processo escolar e da história de muitas famílias das Regiões colonizadas por estrangeiros.

Como apresento no início do texto, a obra organizada por Quadros é um convite à leitura para a compreensão da dimensão do projeto de nacionalização do ensino no Brasil.

Recebido em 21 de dezembro de 2015. Aprovado em 17 de abril de 2016. 